\title{
Estimates of genetic and environmental (co)variances for live weight and fleece traits in yearling South African Mutton Merino sheep
}

\author{
S.W.P. Cloete ${ }^{1,2, \#, ~ J . B . ~ v a n ~ W y k ~}{ }^{1}$ and F.W.C. Neser $^{1}$ \\ ${ }^{1}$ Department of Animal, Wildlife and Grassland Sciences, University of the Free State, PO Box 339, Bloemfontein \\ 9300, South Africa \\ ${ }^{2}$ Elsenburg Agricultural Centre, Private Bag X1, Elsenburg 7607, South Africa
}

\begin{abstract}
Yearling live weight and fleece trait data were obtained from between 2214 and 2270 yearling SA Mutton Merino progeny of the Elsenburg flock during a 20-year period from 1983 to 2002. Information of (co)variances for these traits in SA Mutton Merinos is exceedingly scarce in the literature. Estimates of (co)variance components and ratios were thus obtained from these data, using an Animal Model. Coefficients of variation, for live weight as well as greasy and clean fleece weight were above $18 \%$. Corresponding values for clean yield and fibre diameter were below 9\%. Estimates of heritability were 0.23 for yearling live weight, 0.38 for greasy fleece weight, 0.39 for clean fleece weight, 0.59 for clean yield and 0.67 for fibre diameter. Maternal permanent environmental variance ratios were only significant for live weight, greasy fleece weight and clean fleece weight, amounting to $0.09,0.06$ and 0.06 , respectively. Genetic correlations between yearling live weight and wool weight were positive but low $(0.14$ for greasy fleece weight and 0.13 for clean fleece weight). Those of live weight with clean yield and fibre diameter were zero and 0.22 , respectively. The genetic correlation between greasy fleece weight and clean fleece weight was 0.87 . The genetic correlations of greasy fleece weight with clean yield and fibre diameter were -0.07 and 0.21 , respectively. Corresponding correlations with clean fleece weight were 0.43 and 0.38 , respectively. The genetic correlation of clean yield with fibre diameter amounted to 0.33 . In most cases, the derived values were in agreement with those derived from Merino data sets.
\end{abstract}

Keywords: Fibre diameter, fleece weight, genetic correlations, heritability

${ }^{\#}$ Corresponding author. E-mail: schalkc@elsenburg.com

\section{Introduction}

The South African (SA) Mutton Merino breed is derived from the German Merino. The latter breed was imported to South Africa during 1932, on the advice of Mr. G.J. Schuurman, the then chief training officer for sheep and wool production in the Union of South Africa (Vosloo, 1967). The animals adapted well to local conditions, and further imports were done in 1936, 1937, 1949 and 1954. From a flock maintained at the Elsenburg Agricultural Centre, the breed spread throughout South Africa, and is presently considered as one of the most important dual-purpose breeds in the country. The breed was also used in the development of a number of composite breeds, including the Dohne Merino (Kotzé, 1951), the Dormer (Van Wyk et al, 1993a, b) and the Afrino (Snyman et al., 1995). From an initial distribution of predominantly the Western Cape of South Africa, the breed spread throughout South Africa. At present, SA Mutton Merinos are also exported as seedstock to a number of countries abroad, including Australia (Cloete et al., 2001).

Despite the popularity of the SA Mutton Merino there is very little published information on (co)variance components for yearling live weight and wool traits in the breed. Previous studies mostly revolved around the estimation of (co)variance components for early live weight and growth (Neser et al., 2000). Only one study where present-day animal model methods were applied to yearling live weight and wool trait records could be found in the literature (Cloete et al., 2001). The latter study included a relatively small data set of approximately 1500 records obtained from a SA Mutton Merino stud maintained on the Mariendahl Experimental Farm of the University of Stellenbosch. The stud was maintained on the same property alongside Merino and Dohne Merino studs. Cloete et al. (2001) reported genetic variance ratios for yearling live weight, clean fleece weight and fibre diameter in all three studs, based on data recorded over the period from 1980 to 1994. 
Against this background, genetic (co)variance components and ratios were estimated for yearling SA Mutton Merino sheep in one of the founder flocks for the breed, maintained on the Elsenburg Agricultural Centre in the Western Cape of South Africa.

\section{Material and Methods}

The fully pedigreed SA Mutton Merino stud maintained at the Elsenburg Experimental Farm near Stellenbosch supplied material for the study. The Elsenburg experimental farm is situated about $10 \mathrm{~km}$ north of Stellenbosch at $33^{\circ} 51^{\prime} \mathrm{S}$ and $18^{\circ} 50^{\prime} \mathrm{E}$. The elevation of the site is $177 \mathrm{~m}$, and the average long-term precipitation $606 \mathrm{~mm}$. The climate is Mediterranean, and $77 \%$ of the total rainfall is recorded from April to September. The stud formed the basis of the study by Vosloo (1967).

Pedigrees, as well as data on birth weight and weaning weight of the stud are fully recorded for the period from 1955 to the present. The recording of yearling live weight and wool traits, however, commenced only in 1983. The present study was thus conducted over a 20-year period from 1983 to 2002. Over this period, ewes were joined annually during October-November, to lamb during March-April of the following year. Joining took place in 10 kikuyu (Pennisetum clandestinum) paddocks, ranging in size from 0.3 to 0.5 ha. Groups of approximately 25 ewes were joined to a single sire in a single-sire mating system. In most years ewes also lambed in the same set of paddocks, using a drift-lambing system where dry ewes were drifted ahead to the next paddock on a daily basis. Lambs were weaned at an age of approximately 100 days. After weaning they were separated on sex and maintained in two separate flocks. All lambs were shorn during September-October. They were shorn again during February-March of the following year. At this stage they were also weighed as yearlings, greasy fleece weight was recorded and a wool sample was taken for further evaluation. This sample was used for the analysis of clean yield and fibre diameter. The obtained greasy fleece weight and clean yield percentage were used to derive individual clean fleece weight records. Greasy and clean fleece weights were adjusted to a growth period of 365 days prior to analysis. The recordings described above were made on between 2214 and 2270 individuals. Environmental factors affecting the production traits included year of birth (1983-2002), gender (male or female), age of dam (2 to $7+$ years) and birth type (singles, twins or triplets). A small number of quadruplets were pooled with triplets. The identities of the sire and dam of all progeny were known individually.

The ASREML program (Gilmour et al., 1999) was used for the estimation of the fixed effects, and also subsequently to derive variance components for the respective production traits in univariate analyses. The first analyses involved fitting various combinations of fixed effects and interactions between them to obtain an operational model. Effects found to be significant $(\mathrm{P}<0.05)$ in preliminary analyses were retained in subsequent analyses. Random terms were then added to the operational model, resulting in the following genetic models for analyses (in matrix notation):

$$
\begin{aligned}
& y=X b+Z_{1} a+e \\
& y=X b+Z_{1} a+Z_{2} c+e \\
& y=X b+Z_{1} a+Z_{3} m+e \\
& {[\text { Covariance }(a, m)=0]} \\
& y=X b+Z_{1} a+Z_{3} m+Z_{2} c+e \\
& {[\text { Covariance }(a, m)=0]} \\
& y=X b+Z_{1} a+Z_{3} m+e \\
& {\left[\text { Covariance }(a, m)=A \sigma_{a m}\right]} \\
& y=X b+Z_{3} a+Z_{3} m+Z_{2} c+e \\
& {\left[\text { Covariance }(a, m)=A \sigma_{a m}\right]}
\end{aligned}
$$

In these analyses, $y$ was a vector of observations for the respective yearling traits and $b, a, m$ and $c$ vectors of fixed effects, direct genetic variances, maternal genetic variances and maternal permanent environmental variances respectively. $X, Z_{1}, Z_{2}$ and $Z_{3}$ were the corresponding incidence matrices relating the respective effects to $y$, while e was the vector of residuals. A was the numerator relationship matrix, and $\sigma_{a m}$ the covariance between direct genetic and maternal genetic effects.

It was assumed that:

$$
\mathrm{V}(\mathrm{a})=\mathrm{A} \sigma_{\mathrm{a}}^{2} ; \mathrm{V}(\mathrm{m})=\mathrm{A} \sigma_{\mathrm{m}}^{2} ; \mathrm{V}(\mathrm{c})=\mathrm{I} \sigma_{\mathrm{c}}^{2} ; \mathrm{V}(\mathrm{e})=\mathrm{I} \sigma_{\mathrm{e}}^{2},
$$


with I being identity matrices; $\sigma_{\mathrm{a}}^{2}, \sigma_{\mathrm{m}}^{2}, \sigma_{\mathrm{c}}^{2}$ and $\sigma_{\mathrm{e}}^{2}$ the direct genetic variance, maternal genetic variance and the maternal permanent environmental variance and environmental (residual) variance, respectively. These analyses yielded estimates of genetic and permanent environmental variances. Ratios for direct additive genetic, maternal genetic as well as maternal permanent environmental variances were computed from these estimates. These variances were expressed relative to the total phenotypic variance. Log likelihood tests were conducted to determine the most suitable model for each trait in univariate analyses (Snyman et al., 1996). Subsequently, 2-trait animal models were fitted, allowing the calculation of all relevant direct and maternal correlations between traits, together with the appropriate standard errors. All analyses included the full pedigree file, consisting of 11489 individuals, the progeny of 278 sires and 2015 dams.

\section{Results and Discussion}

Data of between 2214 and 2270 animals were considered for the various traits (Table 1). Coefficients of variation for the quantitative production traits were high, ranging from $18.5 \%$ for live weight to $29.1 \%$ for greasy fleece weight. Corresponding coefficients of variation in Western Australian Merino sheep exceeded 17\% (Cloete et al., 2002). The only other study that could be found on SA Mutton Merinos reported coefficients of variation of respectively $19.3 \%$ for yearling clean fleece weight and $18.8 \%$ for yearling live weight (Cloete et al., 2001). While the coefficient of variation for yearling live weight accords closely with the present study, yearling fleece weight was found to be more variable. The coefficients of variation of clean yield and fibre diameter were below $9 \%$ in the present study, as was also reported by Cloete et al. $(2001 ; 2002)$. Coefficients of variation below $10 \%$ are commonly found for fibre diameter and clean yield, while more variation is expected in the other production traits (Olivier et al., 1994; Snyman et al., 1996). The fixed effects of birth year, gender, age of the dam and birth type were consistent with expectations based on literature results. These results are thus omitted from the Results and Discussion heading of this paper.

Table 1 Descriptive statistics for live weight and fleece traits in yearling SA Mutton Merino sheep

\begin{tabular}{lccc}
\hline Trait & $\begin{array}{c}\text { Number of } \\
\text { observations }\end{array}$ & Mean \pm s.d. & $\begin{array}{c}\text { Coefficient of } \\
\text { variation }(\%)\end{array}$ \\
\hline Live weight $(\mathrm{kg})$ & 2270 & $50.7 \pm 9.4$ & 18.5 \\
Greasy fleece weight $(\mathrm{kg})$ & 2214 & $3.27 \pm 0.95$ & 29.1 \\
Clean fleece weight $(\mathrm{kg})$ & 2214 & $2.15 \pm 0.58$ & 27.0 \\
Clean yield $(\%)$ & 2214 & $66.1 \pm 5.9$ & 8.9 \\
Fibre diameter $(\mu \mathrm{m})$ & 2214 & $23.0 \pm 1.7$ & 7.4 \\
\hline
\end{tabular}

Models of choice for all the traits included at least one random source of variation (Table 2). In the case of quantitative traits (live weight and fleece weight), the "best" model included direct genetic and dam permanent environmental variances. Only the genetic effects were significant in the case of clean yield and fibre diameter.

Table 2 Log likelihood values for the models fitting different random effects for live weight and wool traits of yearling SA Mutton Merino sheep with the "best" models in bold

\begin{tabular}{lccccc}
\hline Effects in model & $\begin{array}{c}\text { Live weight } \\
(\mathrm{kg})\end{array}$ & $\begin{array}{c}\text { Greasy fleece } \\
\text { weight }(\mathrm{kg})\end{array}$ & $\begin{array}{c}\text { Clean fleece } \\
\text { weight }(\mathrm{kg})\end{array}$ & $\begin{array}{c}\text { Clean yield } \\
(\%)\end{array}$ & $\begin{array}{c}\text { Fibre } \\
\text { diameter }(\mu \mathrm{m})\end{array}$ \\
\hline Fixed only & -4441.27 & 205.184 & 920.92 & -4274.77 & -1823.15 \\
$+\mathrm{h}^{2}$ & -4402.39 & 293.845 & 1019.73 & $\mathbf{- 4 1 4 6 . 6 9}$ & $\mathbf{- 1 6 0 1 . 6 3}$ \\
$+\mathrm{h}^{2}+\mathrm{c}^{2}$ & $-\mathbf{4 3 9 3 . 0 9}$ & $\mathbf{2 9 9 . 2 4 3}$ & $\mathbf{1 0 2 4 . 7 8}$ & -4146.33 & -1601.63 \\
$+\mathrm{h}^{2}+\mathrm{m}^{2}$ & -4395.20 & 294.678 & 1020.82 & -4146.55 & -1601.48 \\
$+\mathrm{h}^{2}+\mathrm{m}^{2}+\mathrm{c}^{2}$ & -4392.54 & 299.243 & 1024.78 & -4146.33 & -1601.48 \\
$+\mathrm{h}^{2}+\mathrm{m}^{2}+\mathrm{r}_{\mathrm{am}}$ & -4395.08 & n.c. & 1021.86 & -4145.51 & -1601.40 \\
$+\mathrm{h}^{2}+\mathrm{m}^{2}+\mathrm{c}^{2}+\mathrm{r}_{\mathrm{am}}$ & -4392.14 & n.c & 1025.98 & -4145.41 & -1601.40 \\
\hline
\end{tabular}

(Co) variance ratios: $\mathrm{h}^{2}=$ direct additive; $\mathrm{m}^{2}=$ maternal additive; $\mathrm{c}^{2}=$ maternal permanent environmental ; $\mathrm{r}_{\mathrm{am}}=$ genetic correlation between animal effects, n.c. $=$ no convergence 
Heritability $\left(\mathrm{h}^{2}\right)$ was estimated at 0.23 for yearling live weight (Table 3$)$. This estimate is somewhat lower than the range of estimates for Merinos (0.38 - Olivier et al., 1994; 0.43 - Snyman et al., 1996; 0.45 Brash et al., 1997; 0.52 - Cloete et al., 1998; 0.48 - Purvis \& Swan, 1999; 0.37 to 0.56 - Rose \& Pepper, 1999; 0.52 - Cloete et al., 2002). However, other studies on Merinos yielded somewhat lower estimates (0.28 - Swan \& Hickson 1994; 0.25 to 0.33 - Olivier et al., 1998). Lower $\mathrm{h}^{2}$ estimates were also found in other breeds, namely 0.21 for Targhee sheep (Notter, 1998) and 0.14 to 0.45 for Coopworths (Lewis \& Beatson, 1999). The only previous animal model $\mathrm{h}^{2}$ estimate of 0.45 for yearling live weight in the SA Mutton Merino breed (Cloete et al., 2001) was higher than the present estimate.

Table 3 (Co)variance components and ratios for live weight and wool traits of yearling SA Mutton Merino sheep

\begin{tabular}{lccccc}
\hline Component or ratio & Live weight & $\begin{array}{c}\text { Greasy } \\
\text { fleece weight } \\
(\mathrm{kg})\end{array}$ & $\begin{array}{c}\text { Clean } \\
\text { fleece weight } \\
(\mathrm{kg})\end{array}$ & $\begin{array}{c}\text { Clean yield } \\
(\%)\end{array}$ & $\begin{array}{c}\text { Fibre } \\
\text { diameter } \\
(\mu \mathrm{m})\end{array}$ \\
\hline Variance components & & & & & \\
$\sigma_{\mathrm{a}}^{2}$ & 5.186 & 0.1133 & 0.0584 & 13.181 & 1.4023 \\
$\sigma^{2} \mathrm{c}$ & 1.951 & 0.0177 & 0.0082 & - & - \\
$\sigma_{\mathrm{e}}^{2}$ & 15.136 & 0.1649 & 0.0824 & 9.167 & 0.7038 \\
$\sigma_{\mathrm{p}}^{2}$ & 22.273 & 0.2959 & 0.1491 & 22.348 & 2.1061 \\
Variance ratios & & & & & \\
$\mathrm{h}^{2}$ & $0.23 \pm 0.05$ & $0.38 \pm 0.05$ & $0.39 \pm 0.05$ & $0.59 \pm 0.05$ & $0.67 \pm 0.04$ \\
$\mathrm{c}^{2}$ & $0.09 \pm 0.02$ & $0.06 \pm 0.02$ & $0.06 \pm 0.02$ & - & - \\
\hline
\end{tabular}

Variances: $\sigma_{\mathrm{a}}^{2}-$ Direct additive; $\sigma_{\mathrm{c}}^{2}-$ Maternal permanent environmental; $\sigma_{\mathrm{e}}^{2}-$ Environmental; $\sigma_{\mathrm{p}}^{2}-$ Total phenotypic; Ratios: $\mathrm{h}^{2}$ - Direct additive, $\mathrm{c}^{2}$ - maternal permanent environment

- Effect not significant $(\mathrm{P}<0.05)$

Fleece weight was highly heritable, at slightly below 0.4 . This $\mathrm{h}^{2}$ estimate is in good accordance with values in the literature for Merinos. Estimates of $\mathrm{h}^{2}$ for greasy fleece weight were 0.29 (Swan \& Hickson, 1994), 0.32 to 0.38 (Swan et al., 1995), 0.40 (Brash et al., 1997), 0.23 to 0.35 (Rose \& Pepper, 1999) and 0.44 (Cloete et al., 2002). Corresponding estimates for clean fleece weight were 0.29 (Olivier et al., 1994), 0.28 to 0.31 (Swan et al., 1995), 0.39 (Brash et al., 1997), 0.31 to 0.41 (Taylor et al., 1997), 0.28 to 0.35 (Olivier et al., 1998), 0.29 (Purvis \& Swan, 1999), 0.20 to 0.35 (Rose \& Pepper, 1999) and 0.42 (Cloete et al., 2002). The only other animal model $\mathrm{h}^{2}$ estimate of 0.68 for clean fleece weight in the SA Mutton Merino breed (Cloete et al., 2001) was markedly higher than the present estimate. The wool quality traits (clean yield and fibre diameter) were highly heritable at 0.59 and 0.67 respectively (Table 3). Corresponding animal model $\mathrm{h}^{2}$ estimates for clean yield of Merino types were 0.55 to 0.60 (Swan et al., 1995), 0.41 (Brash et al., 1997), 0.68 (Cloete et al., 1998), 0.52 to 0.60 (Rose \& Pepper, 1999) and 0.63 (Cloete et al., 2002). The $\mathrm{h}^{2}$ estimate for fibre diameter was also consistent with literature values $(0.63-$ Olivier et al., 1994; 0.68 - Snyman et al., 1996; 0.58 - Brash et al., 1997; 0.63 - Cloete et al., 1998; 0.60 Purvis \& Swan, 1999; 0.67 to 0.74 - Rose \& Pepper, 1999; 0.71 - Cloete et al., 2002). In the previous study on SA Mutton Merinos, Cloete et al. (2001) reported an animal model $\mathrm{h}^{2}$ estimate of 0.75 for fibre diameter, which accorded with the present estimate.

Maternal permanent environmental variance ratios accounted for between $9 \%$ (for live weight) and $6 \%$ (for fleece weight) of the phenotypic variation for SA Mutton Merino sheep in the present study (Table 3). Most previous studies on Merino types found maternal genetic effects ranging from 0.01 to 0.15 for live weight, from 0.05 to 0.11 for greasy fleece weight and from 0.03 to 0.17 for clean fleece weight (see estimates summarized from the literature by Cloete et al., 2002). These estimates corresponded with those of the present study with regard to magnitude, although the origin of the maternal effect was the permanent environment in the present study. In the previous study on SA Mutton Merino sheep, the maternal variance (maternal genetic and permanent environmental effects were not separated) amounted to 0.12 for yearling live weight (Cloete et al., 2001).

Genetic, dam permanent environmental, environmental and phenotypic correlations are provided in Table 4. At $13-14 \%$ of the phenotypic variance, the genetic correlations of fleece weight with yearling live 
weight did not reach statistical significance ( $\mathrm{P}<0.05$; i.e. a level of twice the corresponding standard error). It is, however, only slightly below means derived from numerous literature values by Fogarty (1995): 0.21 for greasy fleece weight and 0.18 for clean fleece weight. Estimates for Merinos were $0.30-0.34$ for greasy fleece weight (Brash et al., 1997), and between 0.20 and 0.58 for clean fleece weight (Brash et al., 1997; Purvis \& Swan, 1997; Cloete et al., 2002). Estimates from the present study were well below the majority of these genetic correlations. It may be that the genetic relationship of live weight with fleece weight in SA Mutton Merinos (a dual-purpose breed) is slightly below that of Merinos (primarily a wool breed). The dam permanent environmental correlations of yearling live weight and fleece weight were positive, suggesting that a dam environment favouring live weight would also lead to higher fleece weight. No corresponding estimates were found in the literature. Environmental and phenotypic correlations of fleece weight with yearling live weight were positive, as was reported by Cloete et al. $(1998 ; 2002)$.

Table 4 Correlation estimates ( \pm s.e.) for live weight and wool traits of yearling SA Mutton Merino sheep

\begin{tabular}{lcccc}
\hline \multicolumn{1}{c}{ Traits } & Genetic & $\begin{array}{c}\text { Permanent } \\
\text { environment }\end{array}$ & Environmental & Phenotypic \\
\hline Live weight $\mathbf{x}$ & & & & \\
Greasy fleece weight & $0.14 \pm 0.13$ & $0.53 \pm 0.17$ & $0.54 \pm 0.04$ & $0.41 \pm 0.02$ \\
Clean fleece weight & $0.13 \pm 0.13$ & $0.40 \pm 0.19$ & $0.49 \pm 0.04$ & $0.37 \pm 0.02$ \\
Clean yield & $0.00 \pm 0.12$ & - & $-0.03 \pm 0.05$ & $-0.02 \pm 0.03$ \\
Fibre diameter & $0.22 \pm 0.10$ & - & $0.19 \pm 0.05$ & $0.18 \pm 0.03$ \\
Greasy fleece weight $\mathbf{x}$ & & & & \\
Clean fleece weight & $0.87 \pm 0.03$ & $0.97 \pm 0.03$ & $0.92 \pm 0.01$ & $0.90 \pm 0.01$ \\
Clean yield & $-0.07 \pm 0.10$ & - & $0.00 \pm 0.06$ & $-0.03 \pm 0.03$ \\
Fibre diameter & $0.21 \pm 0.09$ & - & $0.31 \pm 0.05$ & $0.24 \pm 0.03$ \\
Clean fleece weight $\mathbf{x}$ & & - & $0.36 \pm 0.05$ & $0.38 \pm 0.03$ \\
Clean yield & $0.43 \pm 0.08$ & - & $0.20 \pm 0.06$ & $0.28 \pm 0.03$ \\
Fibre diameter & $0.38 \pm 0.08$ & - & $-0.20 \pm 0.06$ & $0.13 \pm 0.03$ \\
Clean yield $\mathbf{x}$ & & - & & \\
Fibre diameter & $0.33 \pm 0.07$ & &
\end{tabular}

- Correlation not estimated

Yearling live weight was not genetically related to clean yield, as was also found by Cloete et al. (2002). Environmental and phenotypic correlations were correspondingly low. The genetic correlation of yearling live weight with fibre diameter was positive, suggesting that heavier SA Mutton Merino sheep will also tend to produce wool with an average thicker diameter. Corresponding genetic correlations in the literature ranged from 0.13 to 0.36 (Brash et al., 1997; Purvis \& Swan, 1997; Cloete et al., 2002). Phenotypic and environmental correlations were generally similar in sign and magnitude to the genetic correlation reported in the present study.

Greasy fleece weight and clean fleece weight were closely correlated at all levels (Table 4). This was expected, since correspondingly high correlations were reported in the literature at our disposal (Atkins, 1997; Brash et al., 1997; Rose \& Pepper, 1999; Cloete et al., 2002). The genetic correlation of greasy fleece weight and clean yield was negative in sign, relatively small in magnitude and not significant $(\mathrm{P}>0.05)$. Corresponding correlations for Merinos in the literature ranged from -0.04 to -0.26 (Swan et al., 1995; Brash et al., 1997; Rose \& Pepper, 1999; Cloete et al., 2002). Clean fleece weight was positively related to clean yield on a genetic level. Literature estimates for Merinos were similar in sign and magnitude, ranging from 0.22 to 0.53 (Swan et al., 1995; Atkins, 1997; Brash et al., 1997; Rose \& Pepper, 1999; Cloete et al., 2002). Phenotypic and environmental correlations between greasy fleece weight and clean yield were low and not significantly different from zero, while those for clean fleece weight were positive. Both measures of fleece weight were positively related to fibre diameter on a genetic level, implying that selection for fleece weight, without considering fibre diameter, would result in wool becoming thicker in diameter. Corresponding genetic correlations concerning clean fleece weight ranged from 0.14 to 0.51(Swan et al., 1995; Atkins, 1997; Brash et al., 1997; Purvis \& Swan, 1997; Rose \& Pepper, 1999; Cloete et al., 2002). The corresponding environmental and phenotypic correlations between fleece weight and fibre diameter 
were similar in sign and somewhat smaller in magnitude than the genetic correlations. The genetic correlation of clean yield with fibre diameter was positive (Table 4). In Merinos, it is often found that these traits are not genetically related (Cloete et al., 1998; 2002).

Heritability estimates for yearling live weight and fleece weight in the present study did not accord well with those derived in the earlier, smaller study by Cloete et al. (2001). This is particularly true in the case of clean fleece weight, where an estimate of 0.63 was previously reported. This value is much higher than most corresponding animal model estimates for Merinos in the literature. The only estimate that remotely resembles it, was a value of 0.62 for Afrino sheep in the study of Snyman et al. (1995). It was argued against the background of the relationship between the SA Mutton Merino and the Afrino (the latter is a composite with a contribution of 50\% from the SA Mutton Merino) that wool weight in the SA Mutton Merino could be highly heritable. The present study does not substantiate this argument, since the derived $\mathrm{h}^{2}$ estimates for SA Mutton Merinos were consistent with those reported for Merinos in the literature. There thus seems to be scope for further studies on the yearling live weight and fleece traits in SA Mutton Merinos, to clear up the discrepancies listed above.

\section{Conclusions}

In conclusion, it was found that most parameter estimates for yearling live weight and wool traits of SA Mutton Merino sheep were in close correspondence with estimates derived from Merino flocks. A discrepancy was live weight, where the $\mathrm{h}^{2}$ estimate was on the lower end of literature estimates. Live weight was also not significantly related to fleece weight on a genetic level in SA Mutton Merinos, although the derived estimates were positive in sign and only slightly below the lower end of those estimated for Merinos. Clean yield in SA Mutton Merinos was furthermore positively related to fibre diameter on a genetic level, a result that was not obtained in Merinos. Further research on wool traits in SA Mutton Merinos is indicated, should the SA Mutton Merino Breeders' Society continue to emphasize wool in their selection strategy.

\section{Acknowledgement}

The authors are indebted to J.E. Fourie for the maintenance and care of the breeding flock and the recording of the data.

\section{References}

Atkins, K.D., 1997. Genetic improvement of wool production. In: The genetics of sheep. Eds: Piper, L.R. \& Ruvinsky, A., CAB International, Wallingford UK. pp. 471-504.

Brash, L.D., Taylor, P.J. \& Gilmour, A.R., 1997. Estimates of genetic parameters and environmental effects for production traits in young Merino rams. Proc. Assoc. Adv. Anim. Breed. Gen. 12, 529-533.

Cloete, S.W.P., Greeff, J.C. \& Lewer, R.P., 2002. Direct and maternal (co)variances for hogget liveweight and fleece traits in Western Australian Merino sheep. Austr. J. Agric. Res. 53, 271-279.

Cloete, S.W.P., Olivier, J.J., Snyman, M.A. \& Du Toit, E., 1998. Genetic parameters and trends in a selection experiment for increased clean fleece weight involving South African Merinos. Austr. J. Exp. Agric. 38, 427-432.

Cloete, S.W.P., Schoeman, S.J., Coetzee, J. \& Morris, J.deV., 2001. Genetic variances for liveweight and fleece traits in Merino, Dohne Merino and SA Meat Merino sheep. Austr. J. Exp. Agric. 41, 145153.

Fogarty, N.M., 1995. Genetic parameters for live weight, fat and muscle measurements, wool production and reproduction in sheep: a review. Anim. Breed. Abstr. 63, 101-143.

Gilmour, A.R., Cullis, B.R., Welham, S.J. \& Thompson, R., 1999. ASREML - Reference manual. NSW Agriculture Biometric Bulletin No. 3. NSW Agriculture, Orange Agricultural Institute, Forest Road, Orange 2800, NSW, Australia.

Kotzé, J.J.J., 1951. The development of a mutton-woolled sheep for the sour-grassveld area. Farming in South Africa April 1951, 110-113.

Lewis, R.M. \& Beatson, P.R., 1999. Choosing maternal effect models to estimate (co)variances for live and fleece weight in New Zealand Coopworth sheep. Livest. Prod. Sci. 58, 137-150.

Neser. F.W.C., Erasmus, G.J. \& Van Wyk, J.B., 2000. Genetic studies on the South African Mutton Merino: growth traits. S. Afr. J. Anim. Sci. 30, 172-177. 
Notter, D.R., 1998. The U.S. National sheep improvement program: Across flock genetic evaluations and new trait development. J. Anim. Sci. 76, 2324-2330.

Olivier, J.J., Erasmus, G.J., Van Wyk, J.B. \& Konstantinov, K.V., 1994. Direct and maternal variance component estimates for clean fleece weight, body weight and fibre diameter in the Grootfontein Merino stud. S. Afr. J. Anim. Sci. 24, 122-124.

Olivier, J.J., Yurgens, Y., Mostert, B.E. \& Erasmus, G.J., 1998. Across-stud evaluation of Merinos in South Africa. Proc. $6^{\text {th }}$ Wrld Congr. Gen. Appl. Livest. Prod. 24, 11-14.

Purvis, I.W. \& Swan, A.A., 1999. Can follicle density be used to enhance the rate of genetic improvement in Merino flocks? Proc. Assoc. Adv. Anim. Breed. Gen. 12, 512-515.

Rose, M. \& Pepper, P.M., 1999. Genetic parameters for production traits in Queensland Merinos. Proc. Assoc. Adv. Anim. Breed. Gen. 13, 114-117.

Snyman, M.A., Erasmus, G.J. \& Van Wyk, J.B., 1995. Direct and maternal (co)variance components and heritability estimates for body weight at different ages and fleece traits in Afrino sheep. Livest. Prod. Sci. 44, 229-235.

Snyman, M.A., Olivier, J.J. \& Olivier, W.J., 1996. Variance components and genetic parameters for body weight and fleece traits of Merino sheep in an arid environment. S. Afr. J. Anim. Sci. 26, 11-14.

Swan, A.A. \& Hickson, J.D., 1994. Maternal effects in Australian Merinos. Proc. $5^{\text {th }}$ Wrld Congr. Gen. Appl. Livest. Prod. 18, 143-146.

Swan, A.A., Lax, J. \& Purvis, I.W., 1995. Genetic variation in objectively measured wool traits in CSIRO'S fine wool flock. Proc. Austr. Assoc. Anim. Breed. Gen. 11, 516-520.

Taylor, P.J., Atkins, K.D. \& Gilmour, A.R., 1999. Genetic association between fibre curvature, staple crimp and wool production and quality of Merino sheep. Proc. Assoc. Adv. Anim. Breed. Gen. 13, 456459.

Van Wyk, J.B., Erasmus, G.J. \& Konstantinov, K.V., 1993a. Non-genetic factors influencing early growth traits in the Elsenburg Dormer sheep stud. S. Afr. J. Anim. Sci. 23, 67-71.

Van Wyk, J.B., Erasmus, G.J. \& Konstantinov, K.V., 1993b. Variance component and heritability estimates of early growth traits in the Elsenburg Dormer sheep stud. S. Afr. J. Anim. Sci. 23, 72-76.

Vosloo, L.P., 1967. Faktore wat die produksie en reproduksie van die Elsenburg Duitse Merinokudde beïnvloed (in Afrikaans). D.Sc. dissertation, University of Stellenbosch, Stellenbosch, South Africa. 